\title{
Experimental study of low Reynolds number effects on aerodynamics of smooth and sinusoidal leading-edge wings in the vicinity of the ground
}

\author{
A.A. Mehraban ${ }^{1}$ and M.H. Djavareshkian ${ }^{1}$ \\ ${ }^{1}$ Department of Mechanical Engineering, Faculty of Engineering,Ferdowsi University of Mashhad, P.O.Box 9177948974, Mashhad, Iran \\ Phone: +989151095791
}

ABSTRACT - Present study experimentally investigates the effects of ground clearance and Reynolds number on aerodynamic coefficients of smooth and sinusoidal leading-edge wings. Wind tunnel tests are conducted over a wide range of angles of attack from zero to 36 degrees, low Reynolds numbers of $30,000,45,000$ and 60,000 , and also ground clearances of $0.5,1$ and $\infty$. Results showed that reduction of ground clearance and increment of Reynolds number cause the lift coefficient and the lift to drag ratio of both wings to be enhanced. Furthermore, the effects of Reynolds number and ground clearance on the smooth leading-edge wing are more than the sinusoidal leading-edge one. In addition, the sinusoidal leading-edge wing shows an excellent performance in the poststall region due to producing a higher lift and also by delaying the stall angle compared to the smooth leading-edge wing.
ARTICLE HISTORY

Received: $26^{\text {th }}$ June 2020

Revised: $13^{\text {th }}$ Oct 2020

Accepted: 07th Jan 2021

\section{KEYWORDS}

sinusoidal leading-edge; ground effect; experimental aerodynamic; low Reynolds number; flow control

\section{INTRODUCTION}

Due to outstanding performance in the poststall region, sinusoidal leading-edge wings have attracted many attentions. These types of wings, which have been inspired by flippers of humpback whales, not only are able to delay the stall angle but also could produce the higher lift force after the stall region compared to unmodified wings. Therefore, there are a great number of studies in the literature which have investigated the effects of leading-edge protuberances on the fluid structure and the aerodynamic performance [1]. Many of these studies have focused on geometric parameters like wavelength [2], amplitude [3], aspect ratio [4], taper ratio [5], sweep angle [6] while the others have taken into consideration the effects of inflow regimes. Indeed, applicability and also aerodynamic performance of these types of wings could be changed when the Reynolds number is varied. The flow regime that recently has been very popular among scientists is low Reynolds numbers because many micro aerial vehicles work in this range. Popularity of sinusoidal leading-edge wings in low Reynolds numbers could be attributed to their efficiency as a means of the flow control to improve aerodynamics of micro aerial vehicles compared to traditional methods like thermal camber phenomenon [7] or boundary layer suction [8]. While classical flow control methods are very energy consuming and also lead to a weight penalty, sinusoidal leading-edge wings as a way of passive flow control would be a remarkable achievement.

Guerreiro and Sousa [4] experimentally examined the capability of a sinusoidal leading-edge wing for being used in micro aerial vehicles. Since these types of aerial vehicles work in the range of low Reynolds number flows, experiments were conducted in two Reynolds numbers of 70,000 and 140,000. They revealed that excellent performance of sinusoidal leading-edge wings in producing lift force could be extended to lower angles of attack when the Reynolds number is decreased. Zhang, et al. [9] employed a leading-edge-protuberance technique to manipulate the fluid flow around a smooth leading-edge wing in order to achieve a higher aerodynamic performance. They experimentally tested their method in a low Reynolds number of 50,000 and showed that the lift coefficient and lift to drag ratio could be enhanced by a maximum $25 \%$ and $39.2 \%$ in the poststall regime by means of leading-edge protuberances, respectively. The goal of the study conducted by Rostamzadeh, et al. [10] was to numerically investigate the fluid flow in transitional and nearturbulent regimes around a tubercled wing. They stated that in the turbulent flow regime, the unmodified wing shows a gradual stall and produces a higher lift than the modified wing. This result highlights the importance of Reynolds number on the aerodynamic performance of sinusoidal leading-edge wings. Aerodynamic performance of three wing configurations, including a wing without leading edge tubercles, one with tubercles of constant wavelength and amplitude along the span and the third with tubercles of varying amplitude and wavelength along the span was compared with each other by Sudhakar, et al. [11]. They found out that tubercled wing with variable amplitude and wavelength has the highest performance.

Vedula, et al. [12] focused on transitional Reynolds number regime ( $R e=200,000$ to 400,000) and compared aerodynamics of a biomimetic tubercle leading-edge airfoil and a smooth leading-edge one. They manifested that although the modified airfoil has a gentler stall than the baseline airfoil, its aerodynamic efficiency reduces by $16.6 \%$. Heesu, et al. [13] experimentally visualized the fluid flow around a three-dimensional wing with tubercles. Results indicated that the stall angle is delayed by $7^{\circ}$ and the maximum lift coefficient increases by $22 \%$ at the Reynold number of 180,000 . Post, et al. [14] investigated six bio-inspired wing configurations with smooth and sinusoidal leading-edges at angles of 
attack of -2 to 24 degrees for Reynolds numbers between 100,000 and 500,000. They proved that flow separation happens at first behind the toughs and then the peaks of the sinusoidal leading-edge wings.

Fluid flow around wavy and unmodified airfoils in a transonic flow regime at a Reynolds number of 1,000,000 was studied by Sepetauskas, et al. [15]. They concluded that wavy wings have potential to be used in commercial aircraft wings due to their capability in preventing shock waves. Numerical simulations over finite wings with leading-edge protuberances were conducted by Esmaeili, et al. [16] at a Reynolds number of 140,000. In this study, they compared different turbulence modeling schemes, including RANS and DES, before and after stall regions. Moreover, the capability of the DES approach for an accurate evaluation of flow physics before and after the stall was proved. Wei, et al. [17] investigated the fluid flow around tapered and swept sinusoidal and smooth leading-edge wings in a Reynolds number of 14,000 which is in the range of underwater gliders. Results showed that separations that are observed over the smooth leading-edge wing especially in the outboard region could be suppressed by using a sinusoidal leading-edge. Effects of Reynolds number, ranging from 10,000 to 60,000 , on aerodynamics of sinusoidal and smooth leading-edge wings with a NACA0012 profile were investigated by Yasuda, et al. [18]. They showed that for angles of attack more than 10 degrees, the leading-edge protuberance enhances the lift coefficient regardless of Reynolds number. Formation of laminar separation bubbles on a sinusoidal leading-edge wing was numerically and experimentally investigated by Sreejith and Sathyabhama [19] at a Reynolds number of 100,000. They found that the flow structure is considerably changed by using a sinusoidal leading-edge. Authors have recently investigated the role of smart flaps in the aerodynamic performance of sinusoidal and smooth leading-edge wings. Results showed that the stall angle could be further delayed by adding a smart flap to the trailing-edge of the sinusoidal leading-edge wing[20]. Effects of the spanwise distribution of tubercles on the wing of a unmanned aerial vehicle were numerically investigated by Papadopoulos, et al. [21]. They showed that aerodynamic performance and efficiency increase in the Reynolds number range between 500,000 and 1,000,000 by applying tubercles.

Another way of flow manipulation to improve the aerodynamic performance is to use wings in the vicinity of the ground where downwash velocity is reduced. This, in turn, causes the effective angle of attack to be increased, resulting in a drag reduction and a higher lift to drag ratio [22]. Johansson, et al. [23] have shown why bats would like to fly in the ground proximity. They found that the aerodynamic power of bats could be reduced by $29 \%$ when they fly near the ground. An experimental study was performed by Jung, et al. [24] to investigate aerodynamic coefficients of a NACA6409 airfoil in the vicinity of the ground over a wide range of angles of attack, aspect ratios and ground clearances. They concluded that the lift to drag ratio increases in low ground clearances and the center of pressure is moved toward the leading-edge. The ground effects on the aerodynamic performance of smart flaps were numerically investigated by authors in two and three dimensions $[22,25]$. Results showed that the tip vortex of the flap and wing is diminished in a low ground clearance. In another research study, authors studied the physics of fluid around an oscillating hydrofoil near water free surface [26].

To summarize, many studies have been conducted to investigate fluid flow characteristics and aerodynamic coefficients around sinusoidal leading-edge wings. These studies either focused on investigation of geometric parameters or inflow regimes. However, to the authors' knowledge, the aerodynamic performance of sinusoidal leading-edge wings in the vicinity of the ground has not been investigated yet. Furthermore, as shown, there are only few studies about the role of low Reynolds numbers in aerodynamics of sinusoidal leading-edge wings. Therefore, the main objective of the present study is to experimentally investigate the effects of Reynolds number and ground clearance on aerodynamics of sinusoidal and smooth leading-edge wings. Lift and drag coefficients of these wings are measured in the wind tunnel over a wide range of angles of attack from zero to 36 degrees, Reynolds numbers of 30,000, 45,000 and 60,000 and ground clearances of $0.5,1$ and $\infty$.

\section{METHODS AND MATERIALS}

Wind tunnel tests are performed in order to investigate the effects of low Reynolds numbers and ground clearances on aerodynamics of sinusoidal and smooth leading-edge wings. In this section, fabrication of wings is explained after defining the problem in detail. Next, the wind tunnel characteristics and measurement devises together with their accuracy are introduced.

\section{Problem Statement}

This study is conducted in the low Reynolds numbers of 30,000, 45,000 and 60,000. In order to investigate the ground effects, three distances to the ground $(H)$ normalized with the mean chord of the wings $(C)$ are considered. Two of these distances are in the vicinity of the ground $(H / C=0.5$ and 1$)$, while the other one is far from it $(H / C=\infty)$. As shown in Figure $1, H$ is defined at the last two-thirds of the chord at mid span. Lift and drag forces of both wings are measured in each aforementioned Reynolds number and ground clearance for a wide range of angles of attack from zero to 36 degrees. The aerodynamic performance of the wings or the lift to drag ratio is also presented in this study for each case to highlight the overall effects of Reynolds number and ground clearance on aerodynamics of sinusoidal and smooth leading-edge wings. 


\section{Preperation of Wings}

As shown in Figure 2, two wings with different leading-edge configurations are considered in this study. The wing with the smooth leading-edge is named wing A and the other one with the sinusoidal leading-edge is called wing B. Both wings have a NACA $63_{4}-021$ profile with a chord and a span of $10.2 \mathrm{~cm}$ and $20.4 \mathrm{~cm}$, respectively. The amplitude and wavelength of the sinusoidal leading-edge wing are $0.12 \mathrm{c}$ and $0.5 \mathrm{c}$, respectively. The design procedure of the sinusoidal leading-edge wing in the current study is the same as that mentioned by Lohry, et al. [27]. Both wings are firstly designed in SolidWork software and then fabricated via a 3D printer. These wings are hand polished after construction and their surface roughness height is much less than the critical roughness height mentioned by Custodio, et al. [3].

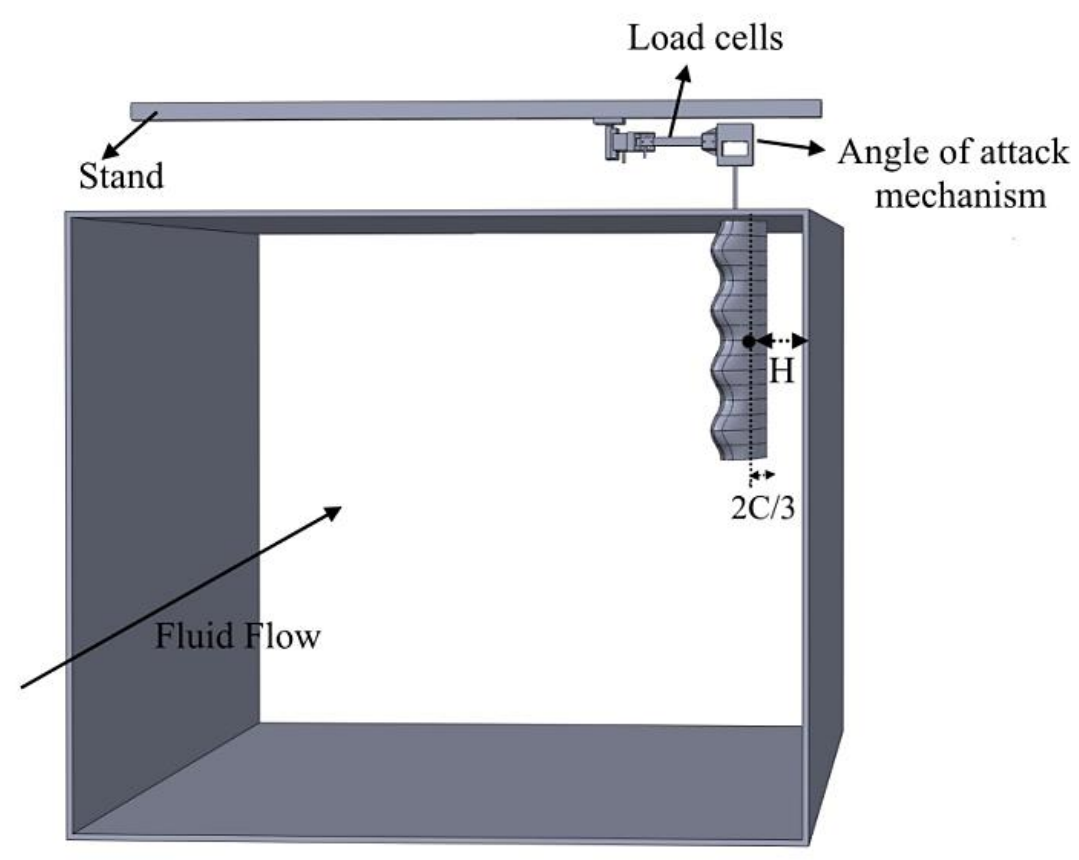

Figure 1. Schematic of the wings inside wind tunnel

\section{Wind Tunnel and Measurement Instruments}

The experiments are conducted in an open circuit, low speed, and closed test section wind tunnel with a test section of $120 \mathrm{~cm} \times 100 \mathrm{~cm}$. The turbulence intensity of the wind tunnel is $0.3 \%$ at a velocity of $5 \mathrm{~m} / \mathrm{s}$. This value for turbulence intensity is much less than that mentioned by Mueller [28]. In order to measure lift and drag forces, two one-dimensional loadcells previously used in $[29,30]$ are employed. The hysteresis, non-repeatability, and non-linearity of force sensors are less than $0.02 \%$ of full scale $(3 \mathrm{~kg}$ and $6 \mathrm{~kg}$ ). Furthermore, the relative uncertainty in force coefficients was determined to be less than $1 \%$. Forces are acquired for 50 seconds for each case at $1000 \mathrm{~Hz}$. The loadcells are calibrated via known weights and the output functions are used to convert the average measured signals to force. An amplifier (model Dacell DN-AM100) is used to amplify the loadcells' measured voltage and all signals are acquired by using a data acquisition board (model Advantech PCI-1710HG).

Top view

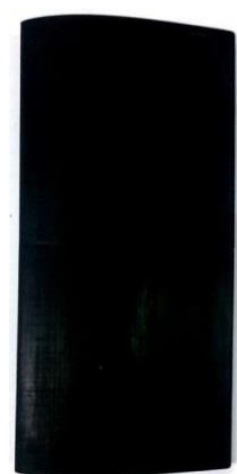

Side view

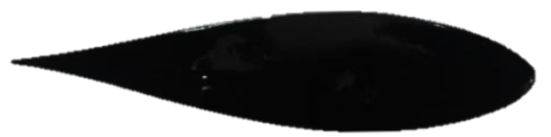

(a) Wing A (Smooth leading-edge) 

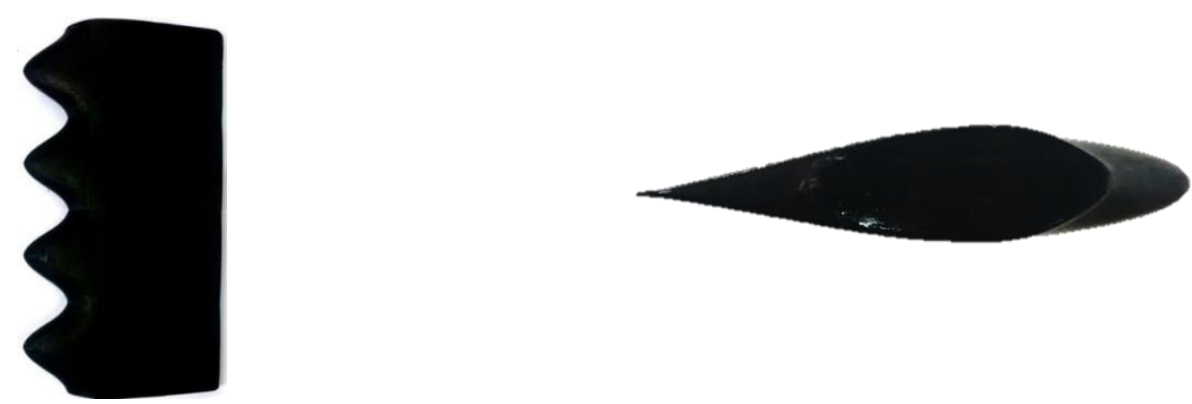

(b) Wing B (Sinusoidal leading-edge)

Figure 2. Top view and side view of fabricated wings: (a) smooth leading-edge wing (wing A) and (b) sinusoidal leading-edge wing (wing B)

In order to change the value of the angle of attack, a mechanism demonstrated in Figure 3 is implemented. In this mechanism, the stepper motor (Figure 3(a)) is exploited to convert the rotational motion of the electrical motor to wings via a radial roller bearing (Figure 3(b)). These components are assembled and then placed into a shield shown in Figure 3(c). Finally, the model is installed inside the wind tunnel which is depicted in Figure 4. It should be noted that in this experiment, in the worst case (lowest Reynolds number), about $2.95 \%$ of wings is in the wind tunnel boundary layer. This content is less than that of Custodio, et al. [3] where the wind tunnel boundary layer covers $4.3 \%$ and $7.8 \%$ of the model span for the largest and smallest freestream velocities, respectively.

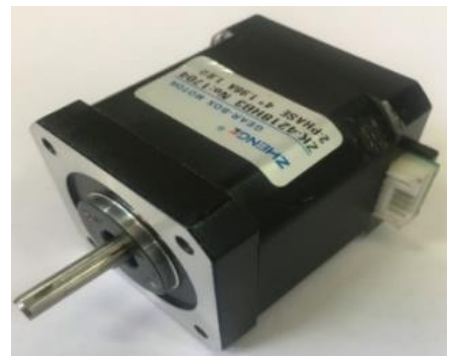

(a)

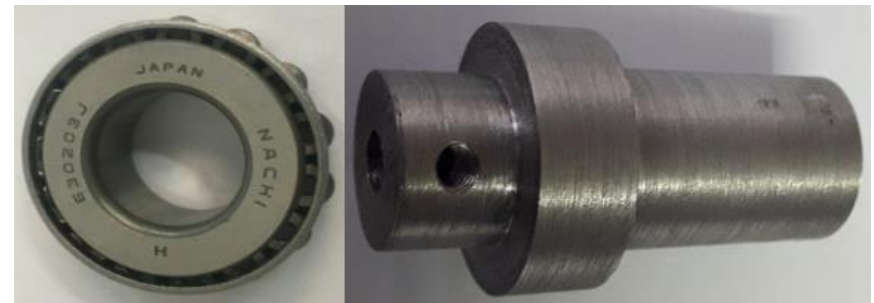

(b)

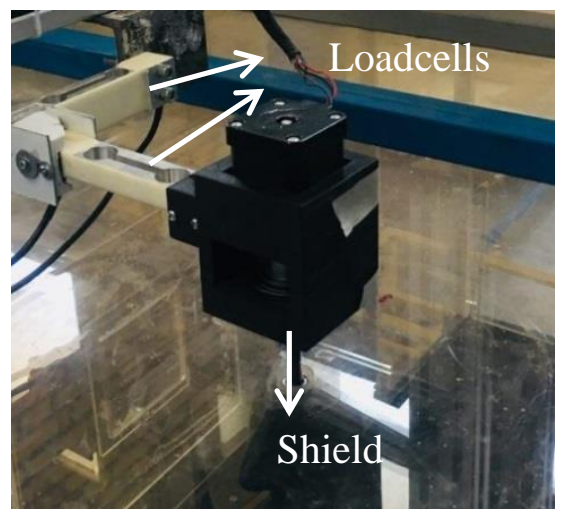

(c)

Figure 3. Constructed mechanism for variation of angle of attack: (a) stepper motor, (b) radial roller bearing, and (c) shield 

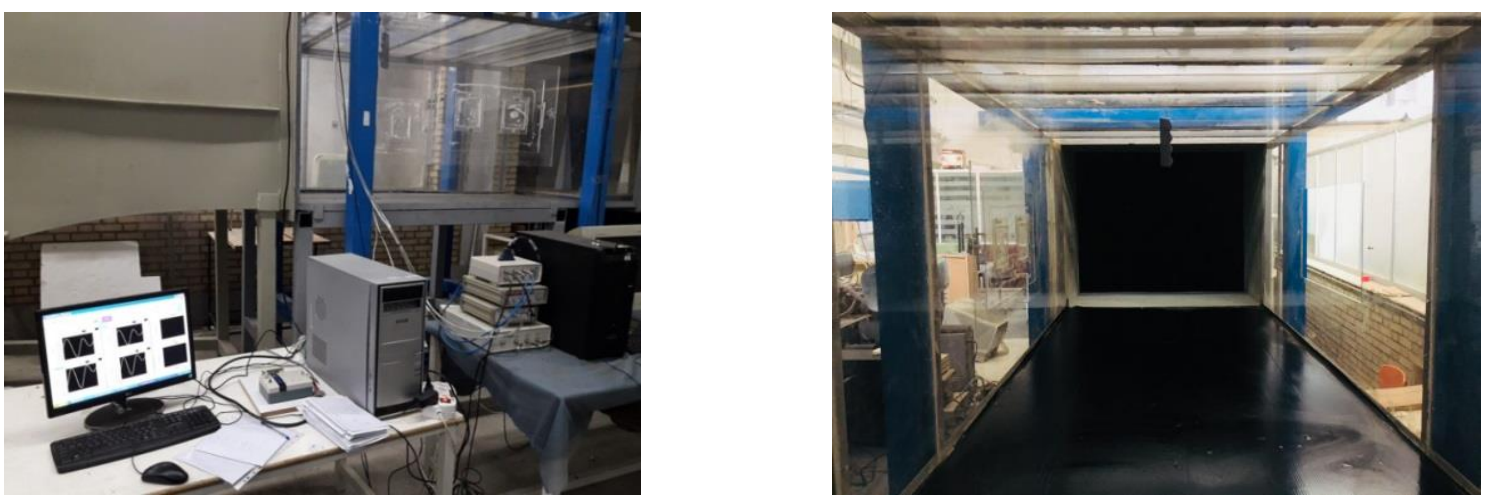

Figure 4. View of model inside the wind tunnel

\section{Validation}

In order to make assurance that experimental methodology employed in this study is reliable, lift and drag coefficients of the sinusoidal leading-edge wing are compared to those of Custodio, et al. [3] at a Reynolds number of 90,000. As shown in Figure 5, lift and drag coefficients obtained from this study could acceptably follow those of Custodio, et al. [3]. Furthermore, the average error between lift and drag coefficients of the present study and those of Custodio, et al. [3] is equal to $3.7 \%$ and $3.9 \%$, respectively.

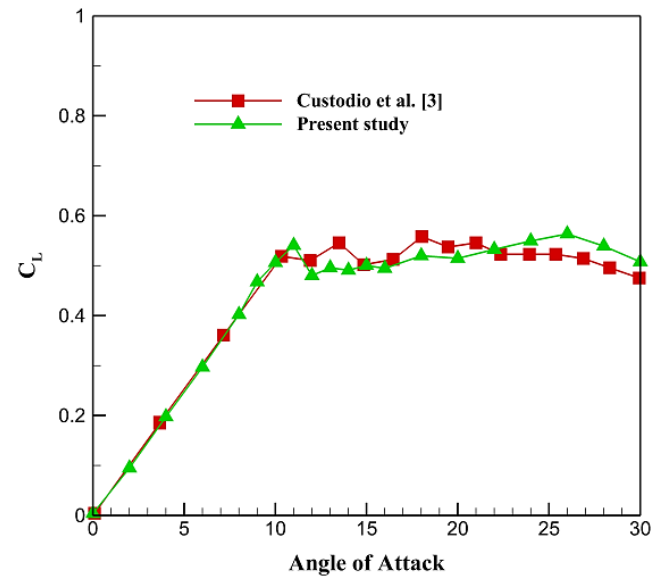

(a)

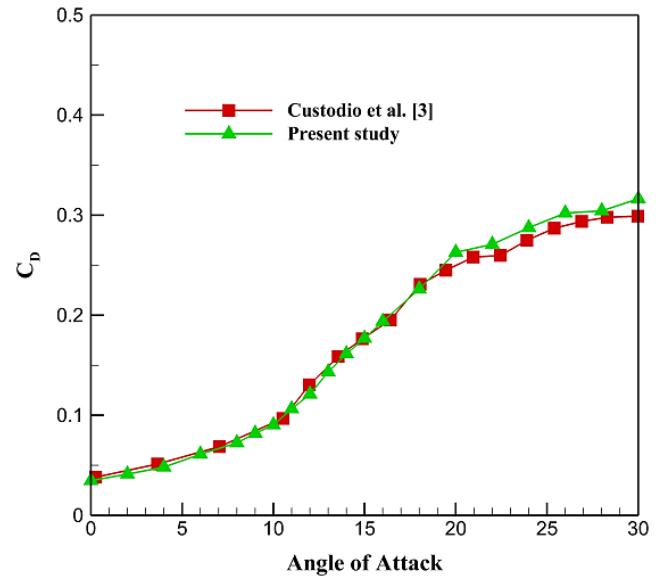

(b)

Figure 5. Comparison between aerodynamic coefficients of this study and those of Custodio, et al. [3]: (a) lift coefficient, and (b) drag coefficient versus angle of attack

\section{RESULTS AND DISCUSSION}

Results obtained from conducting experiments on smooth and sinusoidal leading-edge wings are shown and discussed in this section. Lift coefficient, drag coefficient and lift to drag ratio for two aforementioned wings are plotted versus angle of attack $\left(0^{\circ} \leq A O A \leq 36^{\circ}\right)$ to firstly investigate the effects of Reynolds number $(\operatorname{Re}=30,000,45,000$ and 60,000$)$, and then to focus on the effects of ground $(H / C=\infty, 1$ and 0.5$)$.

\section{Effects of Reynolds Number}

The lift coefficient of wings A and B in each ground clearance is demonstrated in Figure 6 for different Reynolds numbers. It should be noted that the emphasis in this subsection is on the effects of Reynolds number on aerodynamics of smooth and sinusoidal leading-edge wings. As can be seen from Figure 6, the lift coefficient of both wings in all ground clearances and Reynolds numbers linearly increases with angle of attack up to 12 degrees. After that, the lift coefficient non-linearly enhances and then either stalls or reaches a constant value.

The lift coefficient of both wings enhances with increment of Reynolds number regardless of ground clearance. However, the range of variation from $R e=45,000$ to 60,000 is much less than that from $\operatorname{Re}=30,000$ to 45,000. Furthermore, wing $\mathrm{A}$ in the lowest Reynolds number does not experience the intense stall that occurs in the same wing at $R e=45,000$ and 60,000 because in high Reynolds numbers, the flow is attached to the wing surface in low angles of attack. Therefore, 
a strong negative pressure region exists near the leading-edge, leading to increment of the lift coefficient. However, in high angles of attack, an adverse pressure gradient is formed over the upper surface of the wing due to the passage of the laminar flow. After that, because of the inherent lower kinetic energy of the laminar boundary layer, flow starts to separate as a shear layer. As soon as this shear layer is mixed with the freestream momentum, it reattaches to the wing surface as a turbulent boundary layer near trailing-edge and laminar separation bubbles are formed. It is worth mentioning that as the angle of attack increases, larger separation bubbles are created and the reattachment point moves toward trailing-edge $[31,32]$. Further increment of the angle of attack results in a fully flow separation and consequently a large reduction of the lift coefficient [33]. Guerreiro and Sousa [4] clarified that the abrupt lift reduction after the stall point is mainly due to the burst of separation bubbles formed just before the stall.

On the other hand, in the lowest Reynolds number, flow separation happens even at low angles of attack close to the trailing-edge of wing A where the laminar vortices develop. With an increase in the angle of attack, the separation point moves toward the leading-edge. while separation bubbles are reattached to the wing surface in high Reynolds numbers, the shear layer in the lowest Reynolds number is not able to reattach to the wing surface as a turbulent boundary layer, leading to a higher pressure drag and a poor lift production[33]. Consequently, a high discrepancy is reported between the lift coefficient in $R e=30,000$ and higher ones for wing A. However, this difference becomes smaller in high angles of attack because flow separation is developed for both Reynolds numbers[18]. In addition, an increase in Reynolds number from 45,000 to 60,000 causes the stall angle to be delayed up to 2 degrees in the smooth leading-edge wing.

In contrast to wing A, behavior of the wing B in all Reynolds numbers is almost similar to each other. In the sinusoidal leading-edge wing, longitudinal vortices generated by sinusoidal leading-edge cause the flow to be attached. Therefore, the separation that occurs over the upper surface of the leading-edge leads to a negative pressure distribution at troughs [18]. Consequently, wing B has a higher lift coefficient compared to wing A in the poststall. Indeed, fluid flow is deflected toward the troughs and separated when it reaches the sinusoidal leading-edge wing. Separation bubbles in these zones create a strong negative pressure, resulting in a spanwise pressure gradient. This spanwise pressure gradient, in turn, causes the flow to be moved from peaks to troughs. Therefore, momentum is transferred to the separation region near troughs and flow is reattached [18]. The main difference between wing A and wing B is that the significant stall phenomenon occurs in the smooth leading-edge wing particularly in high Reynolds numbers either does not happen in the sinusoidal leading-edge wing or is considerably delayed. Therefore, wing B generally shows superior performance after the stall region or high angles of attack. As explained, this is because that the sinusoidal leading-edge enforces the flow to be reattached particularly in troughs by generating longitudinal vortices while the flow is separated over wing A.

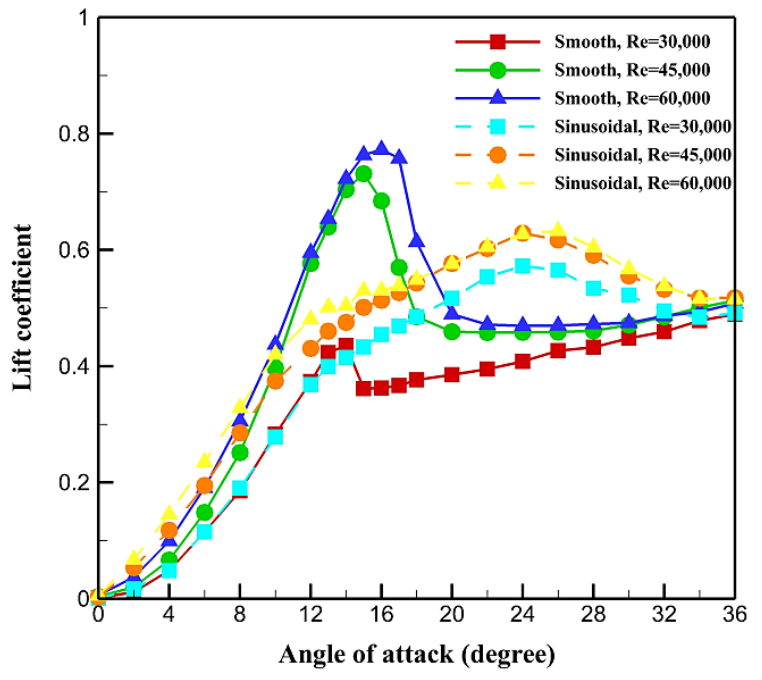

(a) $H / C=\infty$

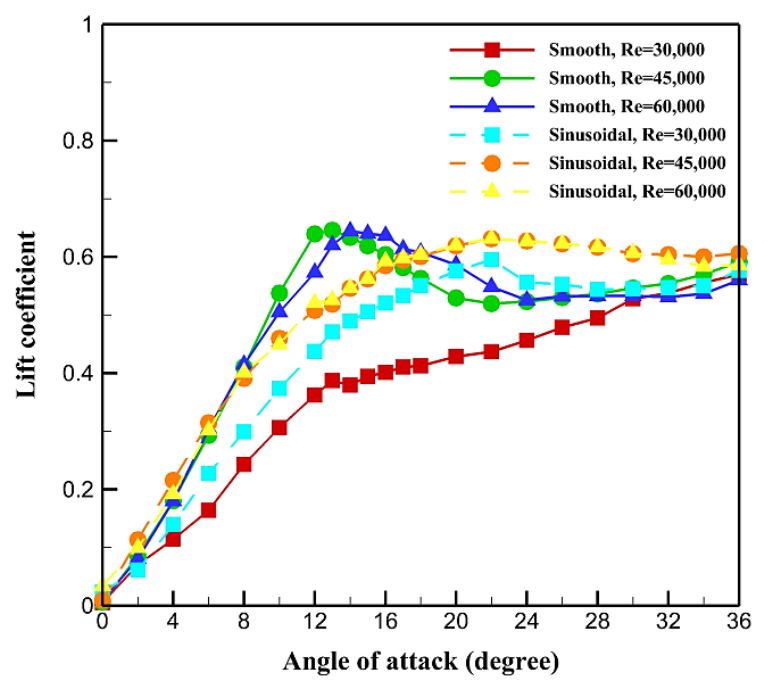

(b) $H / C=1$ 


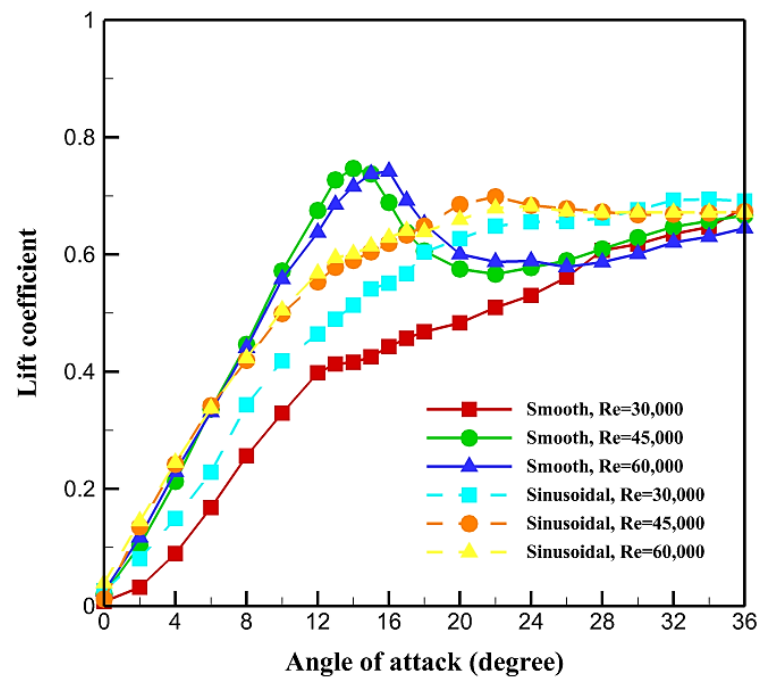

(c) $H / C=0.5$

Figure 6. Lift coefficient of wings A and B for different Reynolds numbers at: (a) $H / C=\infty$, (b) $H / C=1$ and (c) $H / C=0.5$

The drag coefficient of wings A and B in each ground clearance is demonstrated in Figure 7 for different Reynolds numbers. According to this figure, the drag coefficient generally increases with the angle of attack, but angles of attack among 12 to 20 degrees are critical since the drag coefficient of both wings non-linearly goes up in all Reynolds numbers and ground clearances. Furthermore, the drag coefficient of wings A and B in all Reynolds numbers and ground clearances is almost identical for $A O A>20$. In addition, the drag coefficient of both wings decreases with increment of Reynolds number particularly in the vicinity of the ground $(H / C=1$ and 0.5$)$ and before the stall. This reduction in the drag coefficient for wing $\mathrm{A}$ is more than wing $\mathrm{B}$. It should be noted that variation of the drag coefficient with Reynolds number is much less than that of the lift coefficient. That is to say, the drag coefficient is less sensitive to variation of the Reynolds number than the lift coefficient. Moreover, the drag coefficient of wing A is slightly less than that of wing B in the prestall region while the drag coefficient of both wings is almost identical in high angles of attack. This is in agreement to what Yasuda, et al. [18] showed.

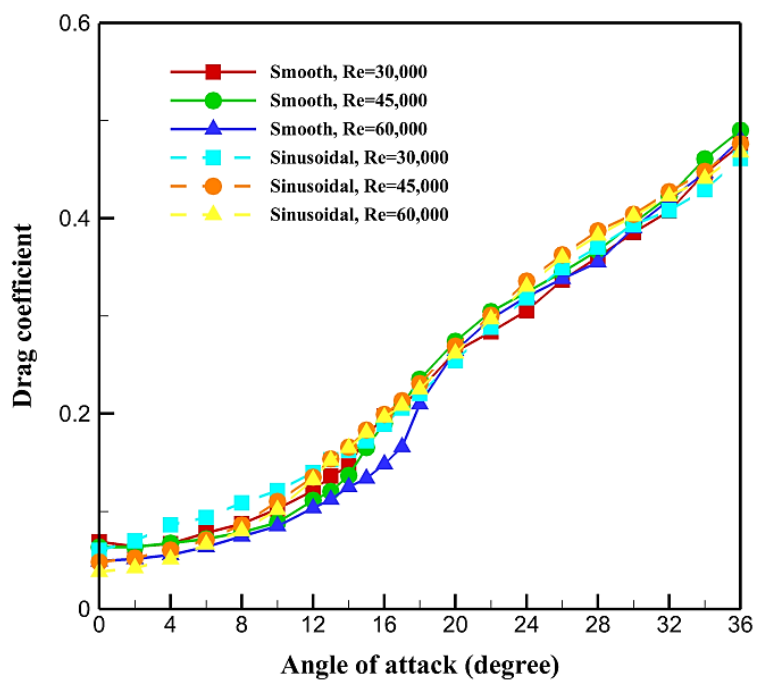

(a) $H / C=\infty$

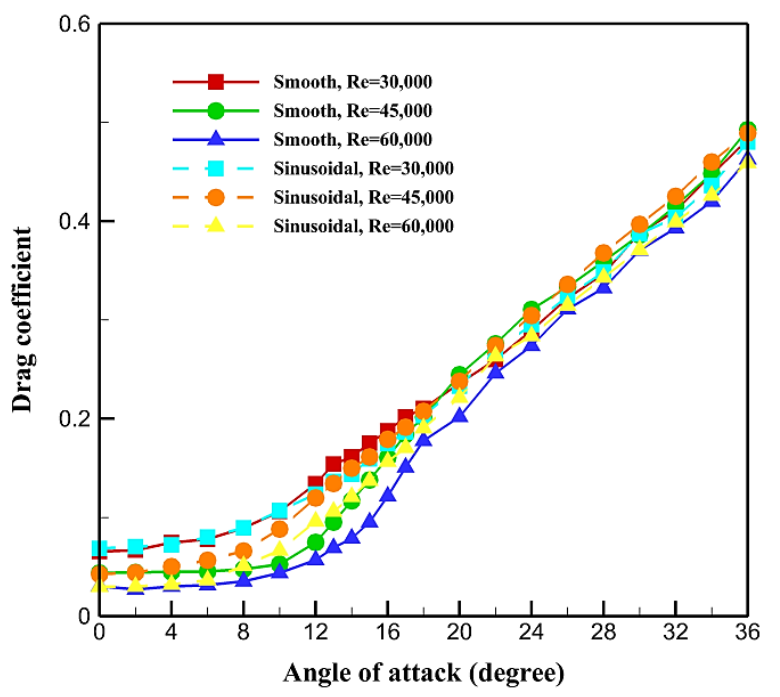

(b) $H / C=1$ 


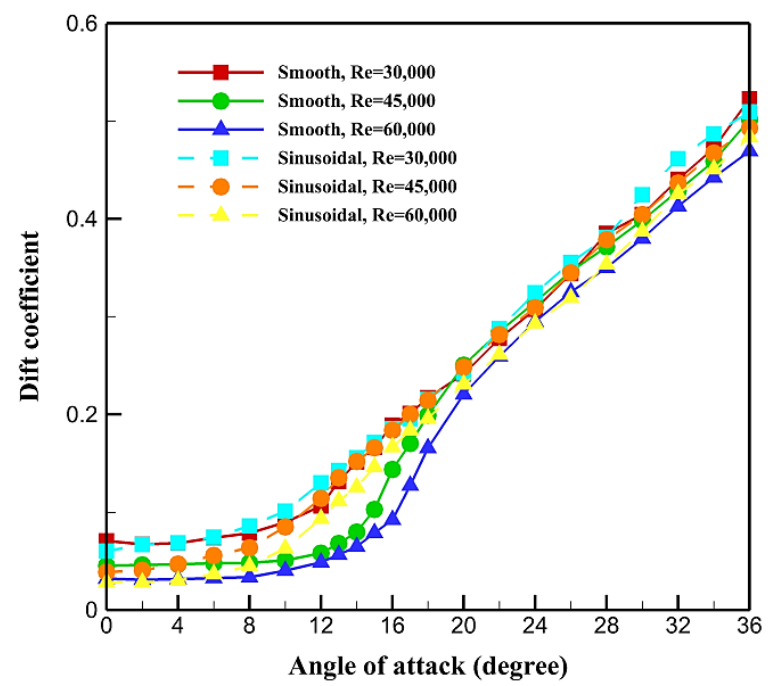

(c) $H / C=0.5$

Figure 7. Drag coefficient of wings A and B for different Reynolds numbers at: (a) $H / C=\infty$, (b) $H / C=1$ and (c) $H / C=0.5$

Lift to drag ratio or aerodynamic performance of wings A and B in each ground clearance is demonstrated in Figure 8 for different Reynolds numbers. As can be seen, the main discrepancy in the aerodynamic performance happens before $A O A<20$, while the lift to drag ratio of both wings in different Reynolds numbers and ground clearances is almost the same after this angle. Furthermore, the aerodynamic performance of wings A and B significantly enhances with Reynolds number especially in the vicinity of the ground. This improvement for wing A is more than wing B. Except Re=30,000, the aerodynamic performance of wing $\mathrm{A}$ is higher than wing $\mathrm{B}$ in all distances to the ground. It should be noted that the maximum lift to drag ratio of both wings is generally advanced with Reynolds number increment.

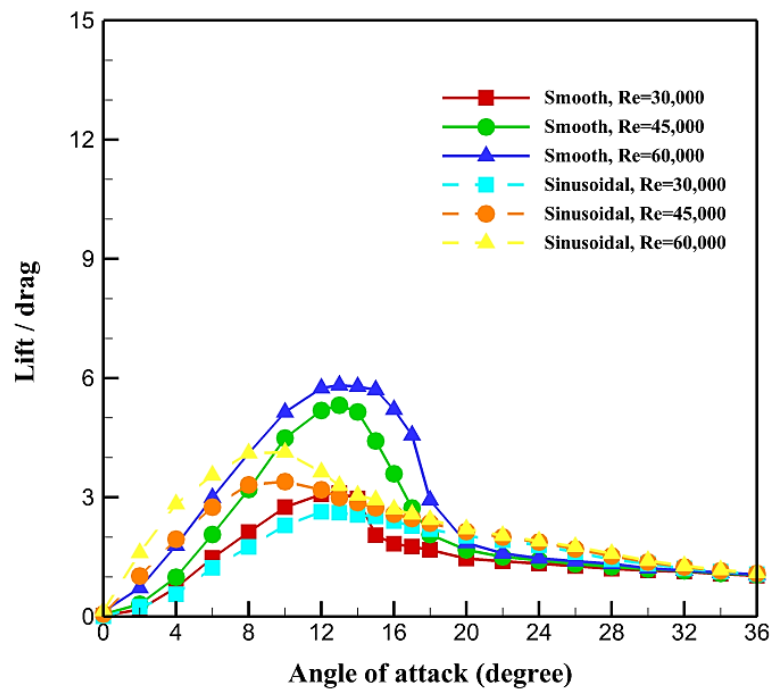

(a) $H / C=\infty$

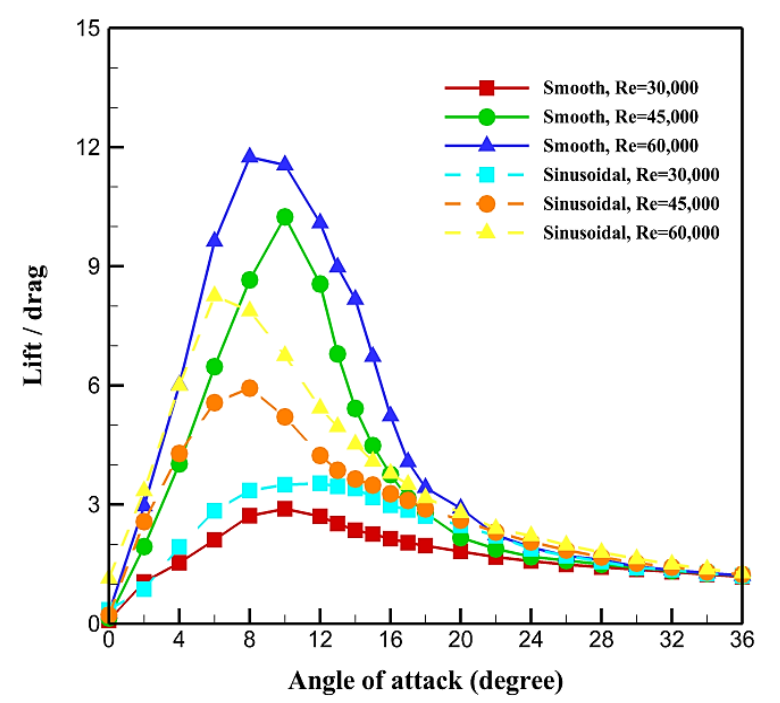

(b) $H / C=1$ 


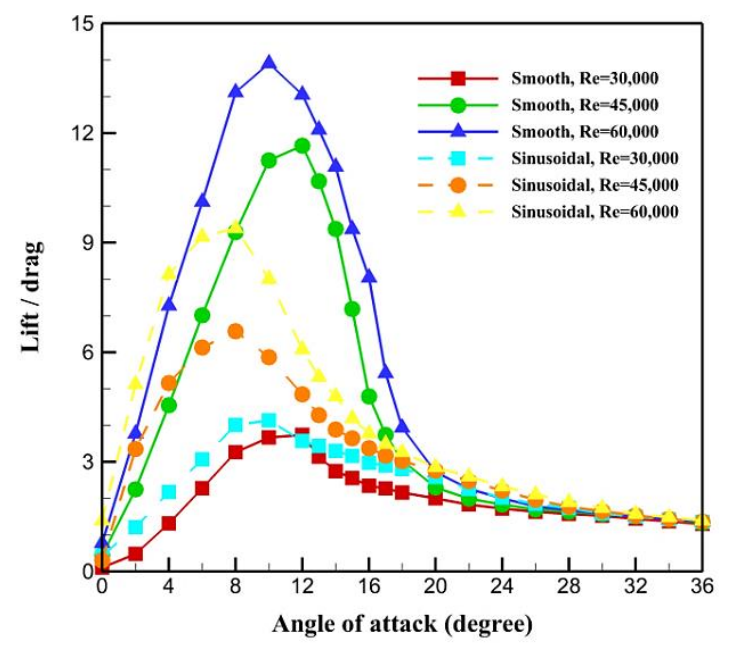

(c) $H / C=0.5$

Figure 8. Aerodynamic performance of wings A and B for different Reynolds numbers at: (a) $H / C=\infty$ (b), $H / C=1$ and (c) $H / C=0.5$

\section{Effects of Ground}

The lift coefficient of wings A and B in each Reynolds number is demonstrated in Figure 9 for different ground clearances. The emphasis in this subsection is on the role of the ground in aerodynamic coefficients of smooth and sinusoidal leading-edge wings. According to Figure 9, the lift coefficient of both wings enhances when they reach the ground in all Reynold numbers. Furthermore, the slope of the lift coefficient curve in the linear region enhances for both wings and all Reynolds numbers when the wings get close to the ground. The best performance of both wings from the lift coefficient point of view happens in the closest distance to the ground (i.e. $H / C=0.5$ ). The converge-diverge shape between the wing lower surface and the ground is the main reason for this superior performance because it causes the pressure to be firstly decreased and then increased. This, in turn, makes a pressure difference around the wing and generates a higher lift than the wing far from the ground[22].

While wing A at $H / C=1$ experiences smoother stall and has much less maximum lift coefficient than the same wing far from the ground, when it gets further closer to the ground $(H / C=0.5)$, it's maximum lift coefficient is comparable to $H / C=\infty$ and it has still smooth stall. On the other hand, the stall phenomenon that occurs for wing $\mathrm{B}$ at $H / C=\infty$ is considerably alleviated when it reaches $H / C=1$. This stall is completely removed when wing $\mathrm{B}$ gets closer to the ground $(H / C=0.5)$. It should be noted that the trend of the lift coefficient diagram for wing $\mathrm{B}$ at $H / C=0.5$ and $R e=30,000$ is entirely upward while it finally reaches a constant value for higher Reynolds numbers.

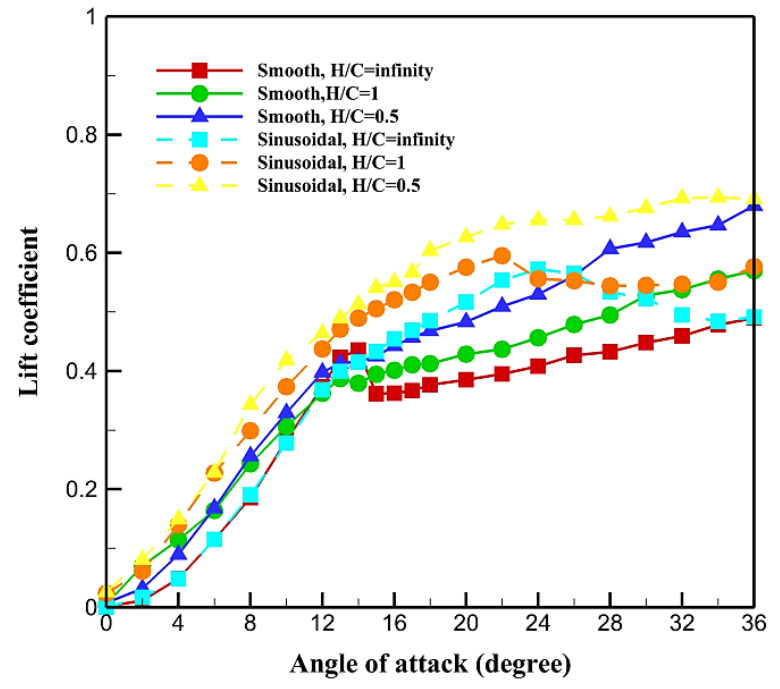

(a) $\operatorname{Re}=30,000$

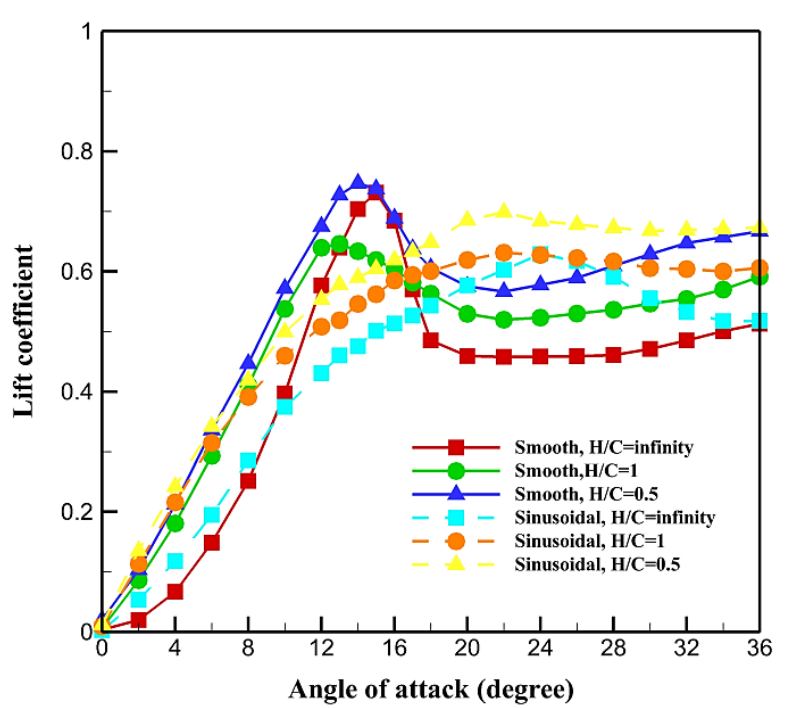

(b) $R e=45,000$ 


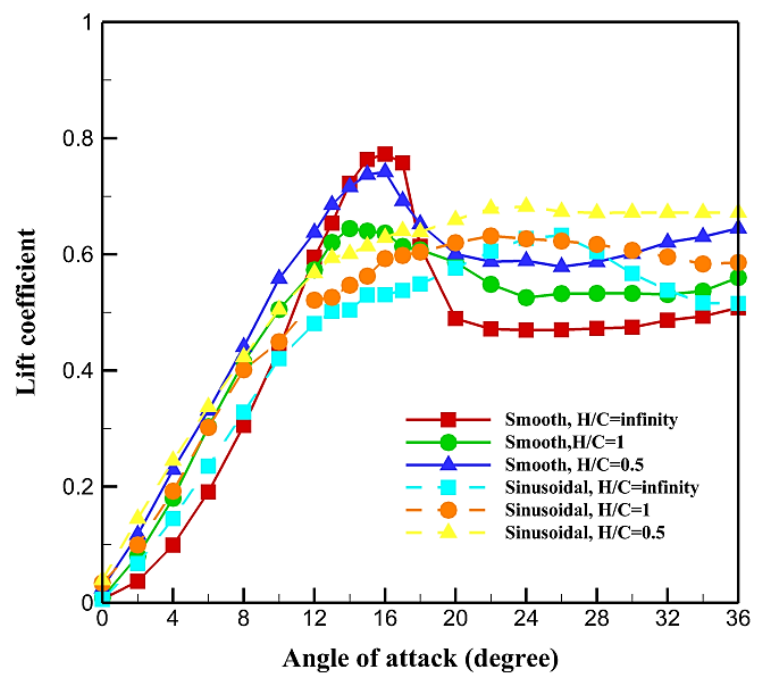

(c) $\operatorname{Re}=60,000$

Figure 9. Lift coefficient of wings A and B for different ground clearances at: (a) $R e=30,000$, (b) $R e=45,000$ and (c) $R e=60,000$

The drag coefficient of wings A and B in each Reynolds number is shown in Figure 10 for different ground clearances. In the lowest Reynolds number, the content of the drag coefficient of both wings at different ground clearances is almost the same for $A O A<28^{\circ}$. After this angle, the drag coefficient of wings $\mathrm{A}$ and $\mathrm{B}$ in the closest distance to the ground $(H / C=0.5)$ has the highest value. However, in $R e=45,000$ and 60,000, the drag coefficient of wings $\mathrm{A}$ and $\mathrm{B}$ is reduced by getting close to the ground for $A O A \leq 24^{\circ}$. This is because the pressure distribution at the lower surface of the wings increases in the vicinity of the ground, leading to a pressure drag increment. In spite of the fact that the surface shear stress over the upper surface of the wing is identical for all ground clearances, the shear stress distribution at the lower surface in the proximity of the ground is less than that far from the ground for low angles of attack. Therefore, wings closer to the ground have less frictional drag[22]. It should be noted that the drag coefficient of wing A is less than wing $\mathrm{B}$ in all ground clearances in particular for $R e=45,000$ and 60,000.

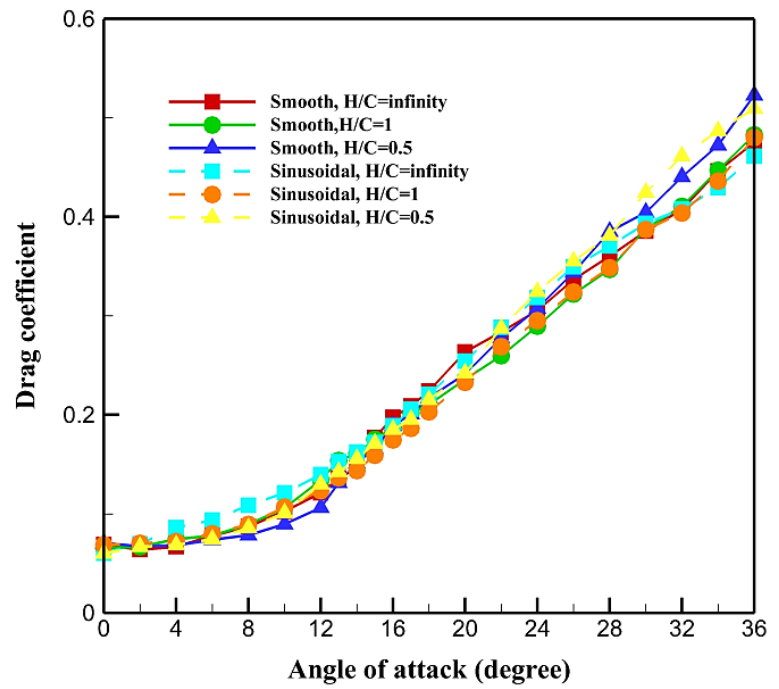

(a) $\operatorname{Re}=30,000$

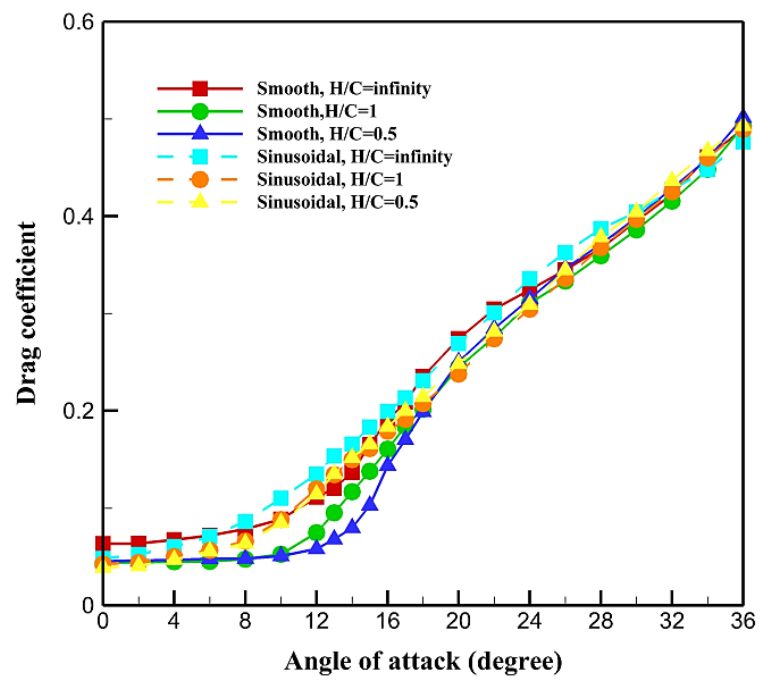

(b) $R e=45,000$ 


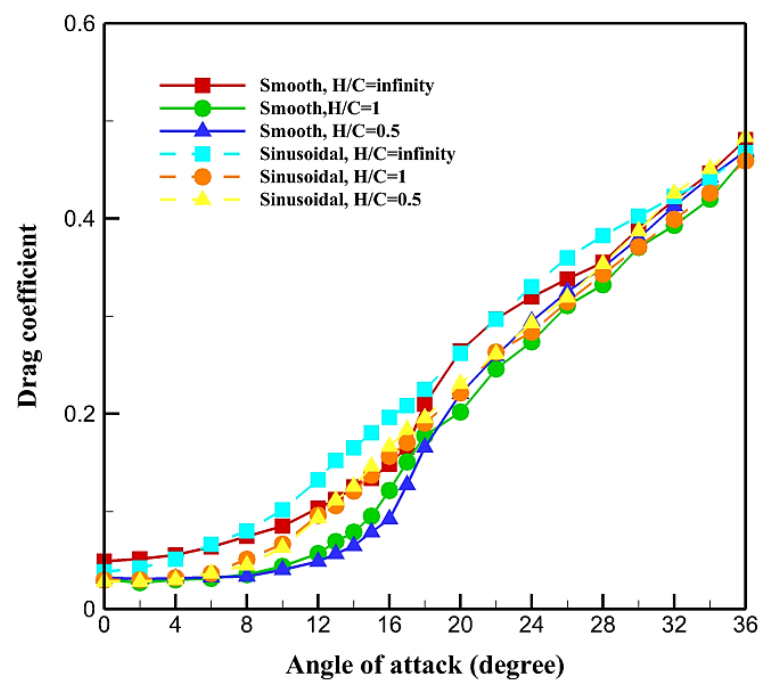

(c) $R e=60,000$

Figure 10. Drag coefficient of wings A and B for different ground clearances at: (a) $R e=30,000$, (b) $R e=45,000$ and (c) $R e=60,000$

Lift to drag ratio or aerodynamic performance of wings A and B in each Reynolds number is shown in Figure 11 for different ground clearances. According to this figure, content of the lift to drag ratio is almost identical for both wings in all ground clearances and Reynolds numbers for $A O A>20^{\circ}$, and the discrepancy emerges before this angle especially for $R e=45,000$ and 60,000 . That is to say, the effects of the ground are drastically enhanced with increment of Reynolds number. Furthermore, wing A is more affected by the ground than wing B. It should also be noted the angle that wing A reaches the maximum aerodynamic performance is higher than that for wing B in all ground clearances and Reynolds numbers.

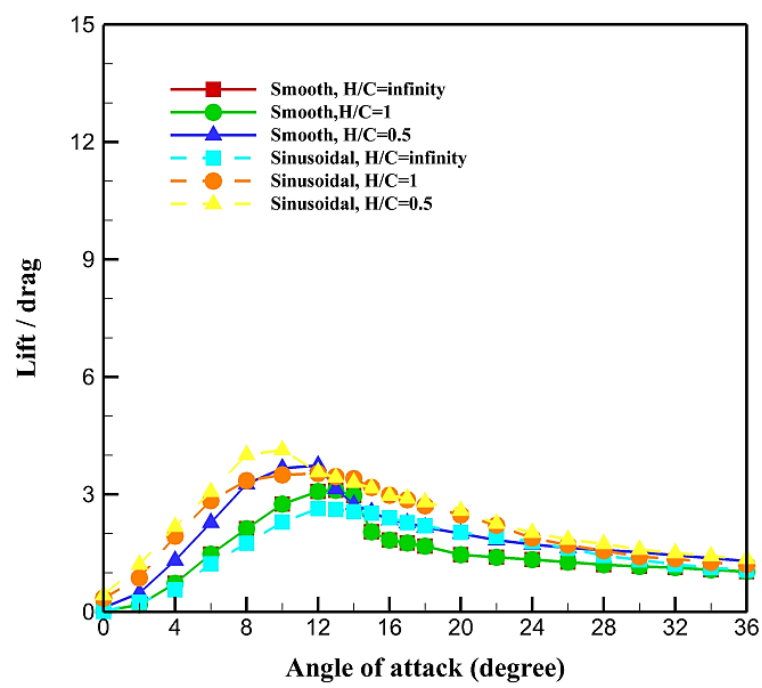

(a) $\operatorname{Re}=30,000$

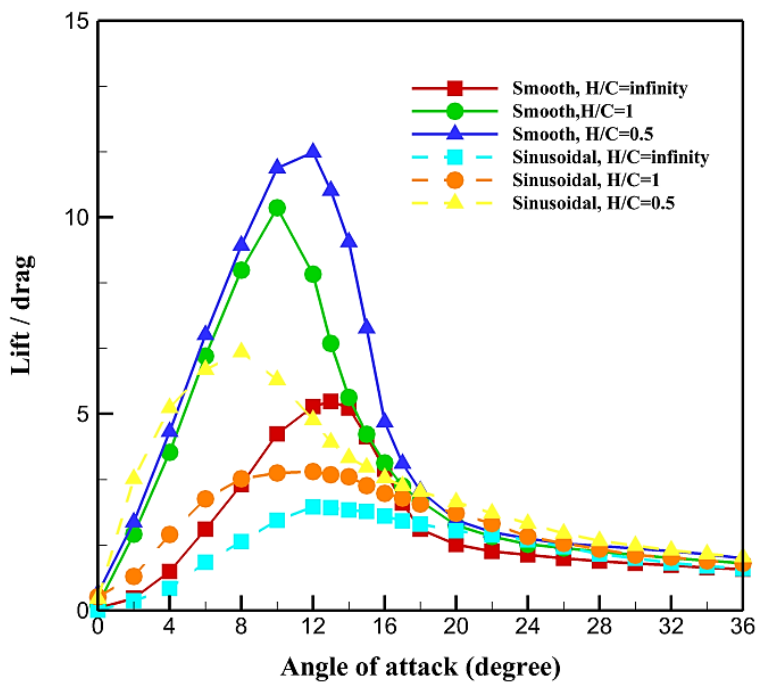

(b) $R e=45,000$ 


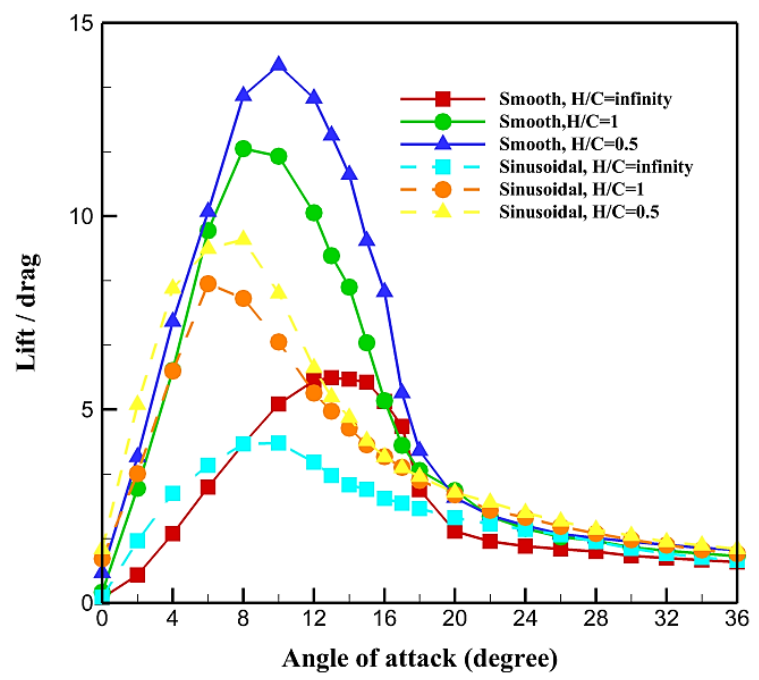

(c) $R e=60,000$

Figure 11. Aerodynamic performance of wings A and B for different ground clearances at: (a) $R e=30,000$, (b) $R e=$ 45,000 and (c) $\operatorname{Re}=60,000$

\section{CONCLUSIONS}

Wind tunnel tests were conducted in the present study to investigate the effects of Reynold number and ground clearance on the aerodynamic performance of sinusoidal and smooth leading-edge wings. Lift coefficient, drag coefficient and lift to drag ratio of these two wings were compared to each other in different low Reynolds numbers of 30,000, 45,000 and 60,000, and different ground clearances of $0.5,1$ and $\infty$ over a wide range of angles of attack from zero to 36 degrees. The main findings of the present study are summarized as follows:

- The lift coefficient and lift to drag ratio of both wings enhance with increment of Reynolds number and reduction of the ground clearance.

- The drag coefficient of both wings decreases with increment of Reynolds number particularly in the vicinity of the ground.

- The smooth leading-edge wing experiences a smoother stall in the vicinity of the ground than the far field case.

- The Sinusoidal leading-edge wing experiences a smoother stall than smooth leading-edge wing in all ground clearances at high Reynolds numbers of 45,000 and 60,000.

- The drag coefficient variation of both wings is more intense in the vicinity of the ground especially for smooth leading-edge one.

- Effects of the ground clearance and Reynolds number on the smooth leading-edge wing are more than the sinusoidal leading-edge one.

- Wing B has a better performance than wing A in the poststall region due to producing a higher lift force and also delaying the stall angle.

\section{REFERENCES}

[1] S. M. A. Aftab, N. A. Razak, A. S. Mohd Rafie, and K. A. Ahmad, "Mimicking the humpback whale: An aerodynamic perspective," Progress in Aerospace Sciences, vol. 84, pp. 48-69, 2016, doi:10.1016/j.paerosci.2016.03.002.

[2] H. Johari, C. W. Henoch, D. Custodio, and A. Levshin, "Effects of leading-edge protuberances on airfoil performance," AIAA Journal, vol. 45, no. 11, pp. 2634-2642, 2007, doi:10.2514/1.28497.

[3] D. Custodio, C. W. Henoch, and H. Johari, "Aerodynamic characteristics of finite span wings with leading-edge protuberances," AIAA Journal, vol. 53, no. 7, pp. 1878-1893, 2015, doi:10.2514/1.J053568.

[4] J. L. E. Guerreiro and J. M. M. Sousa, "Low-Reynolds-number effects in passive stall control using sinusoidal leading edges," AIAA Journal, vol. 50, no. 2, pp. 461-469, 2012, doi:10.2514/1.J051235.

[5] Z. Wei, T. H. New, and Y. D. Cui, "Aerodynamic performance and surface flow structures of leading-edge tubercled tapered swept-back wings," AIAA Journal, vol. 56, no. 1, pp. 423-431, 2017, doi:10.2514/1.J055663.

[6] M. D. Bolzon, R. M. Kelso, and M. Arjomandi, "Force measurements and wake surveys of a swept tubercled wing," Journal of Aerospace Engineering, vol. 30, no. 3, pp. 04016085, 2017, doi:10.1061/(ASCE)AS.1943-5525.0000683. 
[7] A. Samiee, M. H. Djavareshkian, B. F. Feshalami, and E. Esmaeilifar, "Improvement of airfoils aerodynamic efficiency by thermal camber phenomenon at low reynolds number," Journal of Aerospace Technology and Management, pp. 10, 2018, doi:10.5028/jatm.v10.954.

[8] J. Sepahi-Younsi, B. Forouzi Feshalami, S. R. Maadi, and M. R. Soltani, "Boundary layer suction for high-speed air intakes: A review," Proceedings of the Institution of Mechanical Engineers, Part G: Journal of Aerospace Engineering, vol. 233, pp. 3459-3481, 2019, doi:10.1177/0954410018793262.

[9] M. M. Zhang, G. F. Wang, and J. Z. Xu, "Aerodynamic control of low-Reynolds-number airfoil with leading-edge protuberances," AIAA Journal, vol. 51, no. 8, pp. 1960-1971, 2013, doi:10.2514/1.J052319.

[10] N. Rostamzadeh, R. M. Kelso, and B. Dally, "A numerical investigation into the effects of Reynolds number on the flow mechanism induced by a tubercled leading edge," Theoretical and Computational Fluid Dynamics, vol. 31, no. 1, pp. 1-32, 2017, doi:10.1007/s00162-016-0393-x.

[11] S. Sudhakar, N. Karthikeyan, and L. Venkatakrishnan, "Influence of leading edge tubercles on aerodynamic characteristics of a high aspect-ratio UAV," Aerospace Science and Technology, vol. 69, pp. 281-289, 2017, doi:10.1016/j.ast.2017.06.031.

[12] K. Vedula, B. Cetegen, J. Madore, and M. Bellinger, "Biomimetic tubercle leading-edge airfoils in transitional Reynolds number regime," in 2018 Flow Control Conference (AIAA AVIATION Forum: American Institute of Aeronautics and Astronautics, 2018.

[13] K. Heesu, K. Jooha, and C. Haecheon, "Flow structure modifications by leading-edge tubercles on a 3D wing," Bioinspiration \& Biomimetics, vol. 13, no. 6, pp. 066011, 2018, doi:10.1088/1748-3190/aae6fc.

[14] M. L. Post, R. Decker, A. R. Sapell, and J. S. Hart, "Effect of bio-inspired sinusoidal leading-edges on wings," Aerospace Science and Technology, vol. 81, pp. 128-140, 2018, doi:10.1016/j.ast.2018.07.043.

[15] V. A. Sepetauskas, B. Massucatto, A. A. de Paula, and R. G. da Silva, "Wavy leading edge phenomena on transonic flow regime," in 2018 Flow Control Conference (AIAA AVIATION Forum: American Institute of Aeronautics and Astronautics, 2018.

[16] A. Esmaeili, H. E. C. Delgado, and J. M. M. Sousa, "Numerical simulations of low-Reynolds-number flow past finite wings with leading-edge protuberances," Journal of Aircraft, vol. 55, no. 1, pp. 226-238, 2018, doi:10.2514/1.c034591.

[17] Z. Wei, T. H. New, L. Lian, and Y. Zhang, "Leading-edge tubercles delay flow separation for a tapered swept-back wing at very low Reynolds number," Ocean Engineering, vol. 181, pp. 173-184, 2019, doi:10.1016/j.oceaneng.2019.04.018.

[18] T. Yasuda, K. Fukui, K. Matsuo, H. Minagawa, and R. Kurimoto, "Effect of the Reynolds number on the performance of a NACA0012 wing with leading edge protuberance at low Reynolds numbers," Flow, Turbulence and Combustion, vol. 102, pp. 435-455, 2018, doi:10.1007/s10494-018-9978-3.

[19] B. K. Sreejith and A. Sathyabhama, "Experimental and numerical study of laminar separation bubble formation on low Reynolds number airfoil with leading-edge tubercles," Journal of the Brazilian Society of Mechanical Sciences and Engineering, vol. 42, no. 4, pp. 171, 2020, doi:10.1007/s40430-020-2229-2.

[20] A. A. Mehraban, M. H. Djavareshkian, Y. Sayegh, B. Forouzi Feshalami, Y. Azargoon, A. H. Zaree, and M. Hassanalian, "Effects of smart flap on aerodynamic performance of sinusoidal leading-edge wings at low Reynolds numbers," Proceedings of the Institution of Mechanical Engineers, Part G: Journal of Aerospace Engineering, vol. 235, no. 4, pp. 439-450, 2021, doi:10.1177/0954410020946903.

[21] C. Papadopoulos, V. Katsiadramis, and K. Yakinthos, "Influence of tubercles' spanwise distribution on swept wings for unmanned aerial vehicles," Proceedings of the Institution of Mechanical Engineers, Part G: Journal of Aerospace Engineering, vol. 0, no. 0, pp. 0954410020919583, 2020, doi:10.1177/0954410020919583.

[22] M. H. Djavareshkian, A. Esmaeli, and A. Parsani, "Aerodynamics of smart flap under ground effect," Aerospace Science and Technology, vol. 15, no. 8, pp. 642-652, 2011, doi:10.1016/j.ast.2011.01.005.

[23] L. C. Johansson, L. Jakobsen, and A. Hedenström, "Flight in ground effect dramatically reduces aerodynamic costs in Bats," Current Biology, vol. 28, no. 21, pp. 3502-3507, 2018, doi:10.1016/j.cub.2018.09.011.

[24] K. H. Jung, H. H. Chun, and H. J. Kim, "Experimental investigation of wing-in-ground effect with a NACA6409 section," Journal of Marine Science and Technology, vol. 13, no. 4, pp. 317-327, 2008, doi:10.1007/s00773-008-0015-4.

[25] M. H. Djavareshkian, A. Esmaeli, A. Parsania, and A. Ziaforoughi, "Three-dimensional investigation of smart flap aerodynamics for a WIG vehicle," Transactions of the Japan Society for Aeronautical and Space Sciences, Aerospace Technology Japan, vol. 9, pp. 51-60, 2011, doi:10.2322/tastj.9.51.

[26] E. Esmaeilifar, M. H. Djavareshkian, B. Forouzi Feshalami, and A. Esmaeili, "Hydrodynamic simulation of an oscillating hydrofoil near free surface in critical unsteady parameter," Ocean Engineering, vol. 141, pp. 227-236, 2017, doi:10.1016/j.oceaneng.2017.06.037.

[27] M. W. Lohry, D. Clifton, and L. Martinelli, "Characterization and design of tubercle leading-edge wings," In: Seventh International Conference on Computational Fluid Dynamics (ICCFD7), Big Island, Hawaii, pp. 9-13, 2012.

[28] T. J. Mueller, "Aerodynamic measurements at low raynolds numbers for fixed wing micro-air vehicles," Notre Dame University, Department of Aerospace and Mechanical Engineering, 2000.

[29] B. Forouzi Feshalami, M. Djavareshkian, A. Zaree, M. Yousefi, and A. Mehraban, "The role of wing bending deflection in the aerodynamics of flapping micro aerial vehicles in hovering flight," Proceedings of the Institution of Mechanical Engineers, Part G: Journal of Aerospace Engineering, vol. 233, no. 10, pp. 3749-3761, 2019, doi:10.1177/0954410018806081. 
[30] B. F. Feshalami, M. Djavareshkian, M. Yousefi, A. Zaree, and A. Mehraban, "Experimental investigation of flapping mechanism of the black-headed gull in forward flight," Proceedings of the Institution of Mechanical Engineers, Part G: Journal of Aerospace Engineering, vol. 233, no. 12, pp. 4333-4349, 2019, doi:10.1177/0954410018819292.

[31] K. L. Hansen, N. Rostamzadeh, R. M. Kelso, and B. B. Dally, "Evolution of the streamwise vortices generated between leading edge tubercles," Journal of Fluid Mechanics, vol. 788, pp. 730-766, 2016, doi:10.1017/jfm.2015.611.

[32] N. Rostamzadeh, K. L. Hansen, R. M. Kelso, and B. B. Dally, "The formation mechanism and impact of streamwise vortices on NACA 0021 airfoil's performance with undulating leading edge modification," Physics of Fluids, vol. 26, no. 10, pp. 107101, 2014, doi:10.1063/1.4896748.

[33] J. Winslow, H. Otsuka, B. Govindarajan, and I. Chopra, "Basic understanding of airfoil characteristics at low Reynolds numbers (104-105)," Journal of Aircraft, vol. 55, no. 3, pp. 1050-1061, 2018, doi:10.2514/1.c034415. 